\title{
Increased circulating bioactive C-type natriuretic peptide is associated with reduced heart rate variability in patients with chronic kidney disease
}

\author{
Lulu Wang ${ }^{1 \dagger}$, Wenjin $\mathrm{Liu}^{1+} \mathbb{D}^{\text {D }}$, Yanting $\mathrm{Yu}^{1,2}$, Lei Jiang ${ }^{1 *}$ and Junwei Yang ${ }^{1 *}$
}

\begin{abstract}
Background: C-type natriuretic peptide (CNP) is a member of the natriuretic peptide family and have been implicated to be involved in maintaining vascular homeostasis and acting as a cardiac chronotropic agent in experimental studies. However, clinical evidence of its participation in cardiovascular regulation is lacking, especially in patients with chronic kidney disease (CKD). We aimed to explore the association of circulating CNP with cardiovascular alterations in CKD.

Methods: Seventy-six subjects with CKD were recruited. Plasma CNP-22, the bioactive form of CNP in the circulation, was measured by an enzyme immunoassay. The patients also underwent several cardiovascular evaluations including measurement of blood pressure, endothelial function, heart rate variability (HRV) and pulse wave velocity.

Results: Mean ( \pm standard deviation) age of the patients were $59.9( \pm 14.9)$ years and $56.6 \%$ were male. Average plasma CNP level was $790.8 \pm 309.1 \mathrm{pg} / \mathrm{ml}$. Plasma CNP level was not increased as estimated glomerular filtration rate declined. There was no significant difference of CNP between patients with or without endothelial dysfunction (with vs. without endothelial dysfunction: $844.6 \pm 365.5 \mathrm{pg} / \mathrm{ml}$ vs. $738.3 \pm 231.8 \mathrm{pg} / \mathrm{ml}, p=0.14$ ). Plasma CNP showed no association with blood pressure or pulse wave velocity, but was negatively associated with time-domain HRV parameters (SDNN, RMSSD, Triangular Index). The association of CNP with HRV persisted after adjustment for potential covariates.

Conclusions: Our data highlights a possible link between circulating CNP and autonomic dysfunction in CKD patients. Further studies are warranted to explore the mechanisms underlying this association, as well as evaluate the ability of circulating CNP in predicting adverse cardiovascular event in CKD patients.
\end{abstract}

Keywords: CNP, Natriuretic peptide, CKD, Cardiovascular disease, Heart rate variability

\section{Background}

Chronic kidney disease (CKD) is a well-known potent risk factor for developing cardiovascular disease $[1,2]$. Individuals with CKD are more likely to die from cardiovascular causes than to progress to end-stage renal disease [3]. The mechanisms underpinning this increased cardiovascular risk in CKD are complex and remain to be fully elucidated. A variety of non-traditional risk

\footnotetext{
* Correspondence: jianglei@njmu.edu.cn; jwyang@njmu.edu.cn ${ }^{\dagger}$ Equal contributors

${ }^{1}$ Center for Kidney Disease, Second Affiliated Hospital of Nanjing Medical University, 262\# North Zhongshan Road, Nanjing 210003, China

Full list of author information is available at the end of the article
}

factors, as well as traditional ones, have been recognized to be involved in the pathogenesis of cardiovascular injury in CKD [4]. An extensive understanding of the non-traditional factors participating in the modulation of cardiovascular system may therefore provide novel strategy for cardiovascular protection in CKD patients.

C-type natriuretic peptide (CNP) is a cardiovascular bioactive hormone of the natriuretic peptide family and shares structure homology with the other two cardiac peptide, atrial natriuretic peptide (ANP) and B-type natriuretic peptide (BNP) [5]. It is encoded by the Nppc gene on chromosome 2 and is most widely expressed in the brain and endothelial cells [6]. It is synthesized as a 
126 aa peptide (Prepro-CNP) and is converted to the NT-proCNP by removal of the signal peptide. The NT-proCNP is cleaved by furin to yield CNP-53, which is then processed further to yield the bioactive form, CNP-22 [5]. Previous work investigating the biological function of CNP has revealed an important role for it in maintaining vascular homeostasis and blood pressure regulation $[7,8]$. It can also act as a cardiac inotropic and chronotropic agent $[9,10]$. To be noted, the biological activity of CNP are thought to be exerted in a paracrine or autocrine fashion due to the low circulating level. However, recent clinical studies have identified alteration of plasma CNP level in patients with heart failure [11, 12] and have demonstrated a link between elevated plasma CNP and increased risk of myocardial infarction in the general population [13]. These data indicate that circulating CNP is also involved in cardiovascular modulation and diseases.

Although ANP and BNP have been extensively studied in patients with kidney disease, there is a paucity of data regarding CNP and its relationship to cardiovascular alteration in CKD. Questions remain to be answered include: (1) is plasma CNP accumulated as renal function declines? (2) is there any association of circulating bioactive CNP22 with cardiovascular alteration in CKD patients? To answer the questions, we conducted the current crosssectional study. We measured plasma CNP-22 in a group of non-dialysis-dependent CKD patients and explore its association with (1) estimated glomerular filtration rate (eGFR) and (2) several cardiovascular measures which were chosen based on prior experimental evidence, including blood pressure, endothelial function, arterial elasticity and heart rate variability (HRV).

\section{Methods}

\section{Study subjects}

All participants were recruited from the Center for Kidney disease of the Second Affiliated Hospital of Nanjing Medical University. Patients aged over 18 years with a clinical diagnosis of CKD referring to our center were invited to participate in the study. The diagnoses of CKD were made by clinical physicians conforming to the definition of K/DOQI guideline and had been confirmed by study staffs at enrollment. Exclusion criteria were: (1) previous history of renal transplantation; (2) malignancy; (3) acute infection or any other unstable condition. All subjects provided written informed consents. The study protocol was approved by the Institutional Ethical Committee of the Second Affiliated Hospital of Nanjing Medical University.

\section{Cardiovascular evaluations}

All cardiovascular evaluations were performed in the morning with the patients on an empty stomach.
Antihypertensive medications and nitrates were not allowed within $2 \mathrm{~h}$, and long-acting nitrates were not permitted for $12 \mathrm{~h}$ before measurement. Test room temperature was set at $22-25{ }^{\circ} \mathrm{C}$.

Patients rested for $10 \mathrm{~min}$ in a seated position and then underwent three consecutive blood pressure measurements using an automated oscillometric device (Omron HEM-7130; Omron Healthcare Co. Ltd., Kyoto, Japan). Each measurement was separated by 1 min interval. The three measurements were averaged to calculate blood pressure for final analysis.

Carotid-femoral pulse wave velocity (cfPWV) and carotid-radial pulse wave velocity (crPWV) were determined after blood pressure measurement. An experienced technician performed the measurement for all participants using the Complior Analyzer device (Artech Medical; Paris, France). Three probes were placed in a place of palpable pulse of the carotid, femoral and radial artery, respectively. The transit time was averaged over ten consecutive recordings using the intersecting tangent algorithm as recommended [14]. Carotid-femoral and carotid-radial distances were measured and multiplied by 0.8 for calculation of pulse wave velocity.

Endothelial function and HRV were measured via peripheral arterial tonometry using the EndoPAT 2000 (Itamar Medical Inc., Israel). Patients underwent the test in seated position with two finger probes placed on the index finger of each hand. After 6 min of baseline measurement, pulsatile arterial flow was occluded through inflation of a blood pressure cuff on the test arm for $5 \mathrm{~min}$. The cuff was inflated starting at a pressure of $250 \mathrm{mmHg}$ and increased until a complete occlusion was achieved as judged by the PAT signal or to a maximum of $300 \mathrm{mmHg}$. After occlusion, PAT signal was recorded for another $5 \mathrm{~min}$. Reactive hyperemia index (RHI) were calculated automatically by the system [15]. Endothelial dysfunction is defined as $\mathrm{RHI}<1.67$. HRV indices including SDNN (standard deviation of the normal-to-normal interval), RMSSD (the square root of the mean squared differences of successive normal-tonormal intervals), Triangular Index and LF/HF (the ratio of low frequency to high frequency components) is calculated from the baseline period.

\section{Plasma CNP}

Fasting blood were drawn into a EDTA tube to separate plasma. All sample were aliquoted and stored at $-80{ }^{\circ} \mathrm{C}$ until measurement. Plasma CNP was detected by an enzyme immunoassay kit (EKE-012-03, Phoenix Pharmaceuticals, Inc. California, USA). This assay detected the bioactive form of CNP (i.e CNP-22) with a range from 0 to $100 \mathrm{ng} / \mathrm{ml}$. The coefficient of variation at the level of $100 \mathrm{pg} / \mathrm{ml}$ was $16.6 \%$. 


\section{Clinical information}

Demographic and medical information (medical history and medications) were acquired by a combination of patient interview and review of medical records. Previous history of cardiovascular disease refers to any history of acute myocardial infarction, ischemic or hemorrhagic stroke, coronary heart disease other than myocardial infarction, chronic heart failure, atrial fibrillation and other types confirmed by the research staff. All routine laboratory tests were performed in the local Laboratory Department using fasting blood or first voided morning urine. Estimated glomerular filtration rate (eGFR) was calculated using the CKD-EPI formula. CKD stage classification were determined as recommended by the K/DOQI guideline [16].

\section{Statistical analyses}

Data were presented as the mean \pm standard deviation or the median (interquartile range) for numerical variables, and as counts (\%) for categorical variables. Comparisons of CNP levels between groups were performed using Student's t test or the chi-square test as appropriate. To evaluate the relationship of plasma CNP with cardiovascular measures, Pearson's correlation analysis was used. Due to the skewed distribution of HRV parameters, there were logarithm transformed in these analyses. To confirm the association of CNP with HRV, multiple linear regression analyses were conducted with adjustment for several potential covariates, including age, sex, eGFR, diabetes mellitus, body mass index, current smoker, previous history of cardiovascular diseases, hemoglobin and systolic blood pressure. For the selection of covariates, we first checked the associations of all available factors with HRV parameters and found none of them has a consistent association with HRVs ("consistent" defined as significantly associated with at least two HRV parameters) except for sex. Considering the small sample size, our choices of covariates were then mainly determined by whether there is known or expected association with the outcome variable (HRV) which is justified on the basis of previous evidence [17]. All analyses were performed using SPSS 19.0 (IBM SPSS, Chicago, IL). Figures were generated by GraphPad Prism 6.0 (GraphPad Software Inc., San Diego, CA). A two-tailed $p$ value $<0.05$ was considered statistically significant.

\section{Results}

A total of 76 patients participated in the current study. General characteristics of the study patients are presented in Table 1 . Mean ( \pm standard deviation) age of the patients were $59.9( \pm 14.9)$ years and $56.6 \%$ were male. Diabetic kidney disease and glomerulonephritis were the leading causes of CKD in these patients. Mean eGFR was $41.4( \pm 25.4) \mathrm{ml} / \mathrm{min} / 1.73 \mathrm{~m}^{2}$ and $42.1 \%$ patients had
Table 1 General information of the study patients

\begin{tabular}{|c|c|}
\hline & Mean \pm SD / Median (IQR) or N (\%) \\
\hline Age, years & $59.9 \pm 14.9$ \\
\hline Male & $43(56.6 \%)$ \\
\hline $\mathrm{BMI}, \mathrm{kg} / \mathrm{m}^{2}$ & $24.7 \pm 3.7$ \\
\hline Current smoker & $20(26.3 \%)$ \\
\hline \multicolumn{2}{|l|}{ Etiology } \\
\hline Diabetic kidney disease & $22(28.9 \%)$ \\
\hline Hypertensive nephropathy & $6(7.9 \%)$ \\
\hline Glomerulonephritis & $18(23.7 \%)$ \\
\hline Others & $7(9.2 \%)$ \\
\hline Undetermined & $23(30.3 \%)$ \\
\hline Previous CVD & $32(42.1 \%)$ \\
\hline Myocardial infarction & $3(3.9 \%)$ \\
\hline Stroke & $27(35.5)$ \\
\hline Coronary heart disease & $6(7.9 \%)$ \\
\hline Atrial fibrillation & $2(2.6 \%)$ \\
\hline $\mathrm{eGFR}, \mathrm{mL} / \mathrm{min} / 1.73 \mathrm{~m}^{2}$ & $41.4 \pm 25.4$ \\
\hline Hemoglobin, g/L & $112.5 \pm 22.5$ \\
\hline Albumin, $g / L$ & $36.0 \pm 6.9$ \\
\hline Total cholesterol, mmol/L & $5.18 \pm 2.03$ \\
\hline Triglycerides, mmol/L & $1.89 \pm 1.52$ \\
\hline $\mathrm{HDL}-\mathrm{C}, \mathrm{mmol} / \mathrm{L}$ & $1.23 \pm 0.46$ \\
\hline LDL-C, mmol/L & $3.06 \pm 1.23$ \\
\hline Calcium, mmol/L & $2.17 \pm 0.20$ \\
\hline Phosphorus, mmol/L & $1.17 \pm 0.23$ \\
\hline $\mathrm{CRP}, \mathrm{mg} / \mathrm{L}$ & $1.1(0.5-4.0)$ \\
\hline Urine $P C R, \mathrm{mg} / \mathrm{mmol}$ & $246.8(55.6-493.3)$ \\
\hline CNP, pg/ml & $790.8 \pm 309.1$ \\
\hline
\end{tabular}

Abbreviations: BMI Body mass index, CNP C-type natriuretic peptide, CRP Creactive protein, CVD Cardiovascular disease, eGFR Estimated glomerular filtration rate, HDL-C High-density lipoprotein cholesterol, $L D L-C$ Low-density lipoprotein cholesterol, $P C R$ Protein to creatinine ratio

a previous history of cardiovascular disease. Average plasma CNP level was $790.8 \pm 309.1 \mathrm{pg} / \mathrm{ml}$. To evaluate whether renal dysfunction is associated with altered circulating CNP level, we compared plasma CNP concentration in different CKD stages as shown in Fig. 1. Mean plasma CNP was $755.0( \pm 370.7) \mathrm{pg} / \mathrm{ml}, 791.9$ $( \pm 314.7) \mathrm{pg} / \mathrm{ml}$ and $828.2( \pm 211.9) \mathrm{pg} / \mathrm{ml}$ in patients with stage 1-2 CKD, stage 3-4 CKD and stage 5ND CKD, respectively. There was no significant difference between each group $(p=0.84)$.

Endothelial cells are the primary source of circulating CNP in humans. We therefore explored whether patients with endothelial dysfunction exhibit reduced plasma CNP level (Fig. 2). The results indicate that plasma CNP level was comparable between patients with or without endothelial dysfunction (with vs. without 


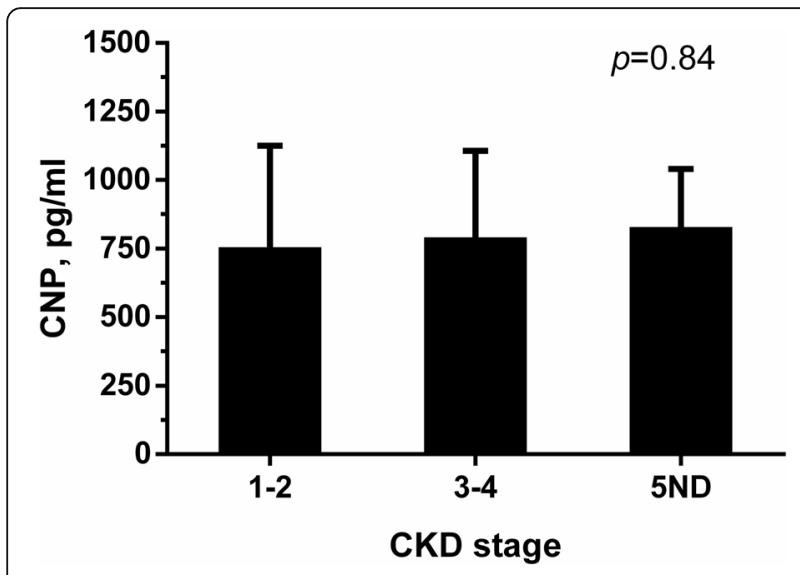

Fig. 1 Plasma CNP levels in different CKD stages. 5ND indicates CKD stage-5 (non-dialysis)

endothelial dysfunction: $844.6 \pm 365.5 \mathrm{pg} / \mathrm{ml}$ vs. $738.3 \pm$ $231.8 \mathrm{pg} / \mathrm{ml}, p=0.14)$.

Cardiovascular evaluation results are presented in Table 2 and their relationships to plasma CNP was evaluated by Pearson's correlation analysis. CNP showed no significant correlation with systolic or diastolic blood pressure, cfPWV or crPWV and RHI, whereas it was correlated positively with heart rate $(r=0.23, p=0.04)$ and negatively with SDNN ( $r=-0.33, p=0.004)$, RMSSD $(r=-0.27, p=0.02)$ and triangular index $(r=-0.33$, $p=0.005$ ) (all HRV parameters were logarithm transformed in Pearson's correlation analyses).

The correlation analysis gave a clue that circulating CNP is associated with altered HRV, rather than vascular homeostasis indices in CKD patients. We hence sought to confirm the associations between CNP and HRV parameters using multiple linear regression analysis with adjustment for several covariates, including age, sex, eGFR, diabetes mellitus, body mass index, current smoker, previous history of cardiovascular diseases,

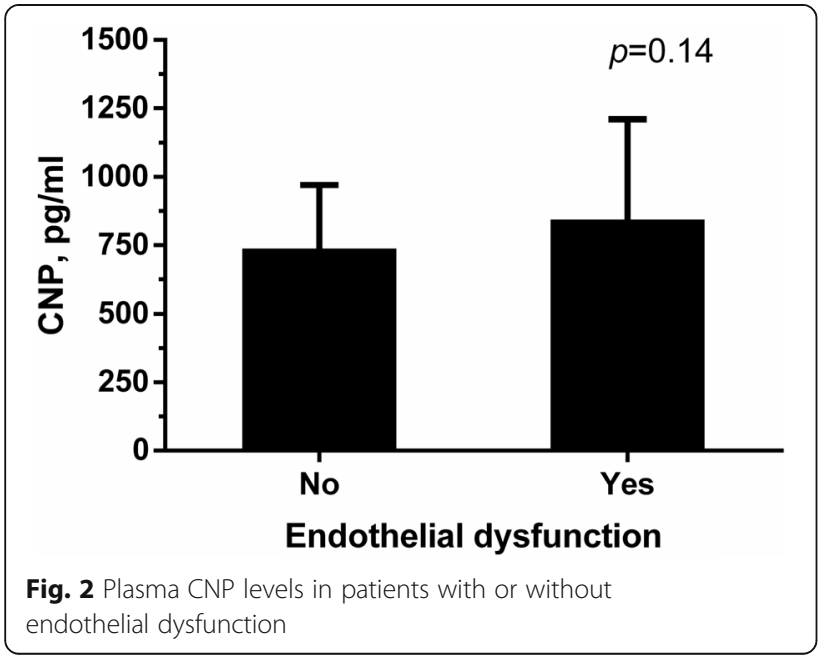

Table 2 Cardiovascular evaluation results and their relationship with plasma CNP

\begin{tabular}{llll}
\hline & Mean \pm SD or Median (IQR) & $r$ & $p$ \\
\hline Systolic BP & $135.8 \pm 20.7$ & -0.04 & 0.74 \\
Diastolic BP & $83.7 \pm 11.5$ & 0.06 & 0.64 \\
Heart rate & $74.8 \pm 12.2$ & 0.23 & $\mathbf{0 . 0 4}$ \\
cfPW & $11.4 \pm 4.3$ & -0.04 & 0.71 \\
CrPW & $10.0 \pm 3.4$ & -0.11 & 0.34 \\
RHI & $1.90 \pm 0.49$ & -0.05 & 0.69 \\
SDNN & $30.8(19.8-57.6)$ & -0.33 & $\mathbf{0 . 0 0 4}$ \\
RMSSD $^{\text {a }}$ & $30.5(17.2-56.3)$ & -0.27 & $\mathbf{0 . 0 2}$ \\
Triangular Index $^{\mathrm{a}}$ & $8.5(5.7-12.0)$ & -0.33 & $\mathbf{0 . 0 0 5}$ \\
LF/HF $^{\mathrm{a}}$ & $0.63(0.32-0.89)$ & 0.04 & 0.75 \\
\hline
\end{tabular}

${ }^{a}$ These parameters were logarithm transformed in Pearson's correlation analysis due to their skewed distribution Bold entries indicate statistical significance

Abbreviations: BP Blood pressure, cfPWV Carotid-femoral pulse wave velocity, CrPWV Carotid-radial pulse wave velocity, IQR Interquartile range, $R H I$ Reactive hyperemia index

hemoglobin and systolic blood pressure. As shown in Table 3, CNP remained significantly associated with logarithm transformed SDNN, RMSSD and triangular index after adjustment (SDNN: $\beta=-0.12, p=0.003$; RMSSD: $\beta=-0.11, p=0.02$; Triangular index: $\beta=-0.08$, $p=0.004$; all $\beta$ were calculated per SD increment of CNP). In a sensitivity analysis excluding patients with coronary artery disease $(n=9)$, the associations remained essentially unchanged (Additional file 1: Table S1).

\section{Discussions}

In the current study, we explored the associations of plasma bioactive CNP with renal function and the cardiovascular system in a group of CKD patients. Our major findings are as following: (1) Increased plasma CNP was associated with reduced HRV; (2) Decreased renal function was not associated with elevated plasma CNP level; (3) Circulating CNP was not reduced in patients with endothelial dysfunction compared to those with preserved endothelial function; (4) There was no

Table 3 Associations between plasma CNP and HRV parameters

\begin{tabular}{llll}
\hline & \multicolumn{3}{l}{ Plasma CNP } \\
\cline { 2 - 4 } & $\beta$ & $95 \%$ confidence interval & $p$ \\
\hline SDNN $^{a}$ & -0.12 & $-0.19--0.04$ & $\mathbf{0 . 0 0 3}$ \\
RMSSD $^{a}$ & -0.11 & $-0.20--0.02$ & $\mathbf{0 . 0 2}$ \\
Triangular Index & -0.08 & $-0.14--0.03$ & $\mathbf{0 . 0 0 4}$ \\
LF/HF $^{a}$ & 0.02 & $-0.08-0.13$ & 0.65 \\
\hline
\end{tabular}

aThese parameters were logarithm transformed in the analysis due to their skewed distribution

$ß$ indicates per SD increment of CNP and was adjusted for age, sex, eGFR, diabetes mellitus, body mass index, current smoker, previous history of cardiovascular diseases, hemoglobin and systolic blood pressure Bold entries indicate statistical significance 
association between plasma CNP and blood pressure or arterial elasticity (neither central or peripheral).

Besides several negative results, we found a significant association of increased plasma CNP with elevated heart rate and reduced HRV. The positive association of CNP with heart rate is in accordance with the chronotropic effect of CNP found in both clinical and experimental settings. Cheung et al. also noted a significant correlation between CNP and heart rate in hypertensive subjects [18]. Moreover, they measured plasma noradrenaline and found a positive association of plasma CNP with noradrenaline. In the study by Igaki et al., intravenous administration of CNP induced an increase of heart rate in healthy subjects [19]. The work by Beaulieu et al. shed light on the underlying mechanism as they found that CNP can increase the maximal depolarization rate during diastole and decrease the action potential duration of repolarization in dogs [10].

The significant and negative association between CNP and HRV in the patients as revealed by our data is very interesting. Since reduced HRV has been proved to be an independent risk factor for cardiovascular events [20], our data may therefore provide insights into the underpinning mechanism of the link between elevated circulating CNP and increased cardiovascular risk in the general population [13]. To the best of our knowledge, our data for the first time show a relationship between CNP and altered HRV in humans and can be interpreted in combination with data from previous experimental settings. In a recent study using a transgenic rat model with neuron-specific overexpression of a dominant negative NPR-B receptor, Buttgereit et al. showed that CNP signaling via the NPR-B receptor is sympathoinhibitory [21]. Noteworthy,overall HRV as assessed by SDNN was reduced in the transgenic rats while LF/HF was increased. In addition, Moyes et al. found increased LF/ HF in female endothelial-specific CNP knock-out mouse with no significant change in SDNN [7]. We observed a negative association of CNP with time-domain indices (SDNN, RMSSD, Triangular index) and no association with LF/HF in CKD patients. Our finding may be a reflection of increased CNP production compensating for autonomic dysfunction in the patients. However, a direct effect of circulating CNP on autonomic regulation can also be possible. The exact explanation remains to be fully elucidated.

Due to increased stimuli and possible reduced renal clearance, plasma natriuretic peptides, including ANP and BNP are generally elevated in patients with impaired kidney function [22-24]. However, in our study, we did not observe an association between plasma CNP and eGFR in patients with CKD. The absence of an association between CNP and eGFR in our study is consistent with a previous report by Sangaralingham et al., in which the authors found no association between CNP and eGFR in the general population [13]. There are two possible explanations for this distinctive characteristic of CNP. First, the production of CNP may be less potent than ANP and BNP in the context of renal dysfunction. ANP and BNP production are mainly stimulated by increased atrial or ventricular wall tension, which is common in CKD patients due to accumulated extracellular fluid volume and elevated blood pressure, whereas $\mathrm{CNP}$ expression regulation remains obscure and has been linked to sheer stress on endothelial cells and cytokines [25, 26]. However, several studies have noted a negative association between NT-proCNP, the propeptide without biological activity, with eGFR [11, 27-29]. Given that no arteriovenous gradient of NT-proCNP was seen across renal tissue, it seems that CNP production, at least at the propeptide level, is also increased in CKD patients. Second, CNP is cleared in the circulation primarily in a kidney-independent fashion. It can be either hydrolyzed by the neutral endopeptidase or bind to the natriuretic peptide receptor- $\mathrm{C}$ to be internalized and degraded [30, 31]. The clearance of CNP in the circulation is very rapid with a half-life of only $2.6 \mathrm{~min}$ [32]. This may also explain that why NT-proCNP, but not CNP, is associated with renal function. To be noted, a previous study observed a negative arteriovenous CNP gradient across renal tissue in humans [27]. This implies that the kidney can also contribute to the clearance of CNP, though may to a less important role.

The endothelium is the primary secretion site of CNP in peripheral tissues [33]. Mice with endothelial-specific knockout of the CNP encoding gene, Nppc, exhibited elevated blood pressure, as well as endothelial dysfunction and impaired endothelial-dependent vascular relaxation capacity $[7,8]$. However, we did not detect a difference in circulating CNP level between patients with endothelial dysfunction and those without. Furthermore, there is also no association of plasma CNP with blood pressure or pulse wave velocity. The lack of a link between circulating CNP and measurements of vascular homeostasis in our study seems to support the questioned notion that the hemodynamic regulation actions of $\mathrm{CNP}$ are paracrine or autocrine, instead of endocrine [19, 34]. This is in line with the findings that polymorphism of the CNP gene was an independent predictor of development of hypertension in a Japanese population but plasma CNP was not increased in hypertensive subjects compared with normotensive controls [18, 35].

Several limitations of our study should be pointed out for proper interpretation of our results. First, due to the cross-sectional design, we cannot draw any causative conclusion. Second, our findings may be somewhat limited by the small sample size and need to be confirmed in population-based studies. The lack of healthy controls 
in the current study leaves the question that whether CNP level differs between individuals with and without CKD unsolved. Third, more detailed cardiac evaluations, e.g. echocardiography or cardiac injury biomarker measurements, were lacking in our study, limiting our ability to explore the association of CNP with cardiac function and injury. Nevertheless, our study remains a first step in evaluating the link between circulating CNP and the cardiovascular system in patents with CKD and can offer indications for further exploration.

\section{Conclusions}

In summary, in a group of patients with CKD, reduced renal function was not associated with elevated plasma CNP. Circulating CNP showed no association with blood pressure, endothelial function or arterial elasticity. There was a significant association between elevated CNP with reduced HRV. Our data highlights a possible link between circulating CNP and autonomic dysfunction in CKD patients. Further studies are warranted to explore the mechanisms underlying this association, as well as evaluate the ability of circulating CNP in predicting adverse cardiovascular event in CKD patients.

\section{Additional file}

Additional file 1: Table S1. Sensitivity analysis excluding patients with coronary artery disease. (DOCX 17 kb)

\section{Abbreviations}

ANP: Atrial natriuretic peptide; BNP: B-type natriuretic peptide; cfPW: Carotid-femoral pulse wave velocity; CKD: Chronic kidney disease; CNP: C-type natriuretic peptide; CrPWV: Carotid-radial pulse wave velocity; eGFR: Estimated glomerular filtration rate; HRV: Heart rate variability; $\mathrm{RHI}$ : Reactive hyperemia index

\section{Acknowledgements}

The authors thank all the study subjects for their participation.

\section{Funding}

The work was supported by Jiangsu Science and Technology Department to Dr. Junwei Yang (Number: BE2017762) and National Science Foundation of China to Dr. Lei Jiang (Number: 31300955/C1102). Jiangsu Science and Technology Department and National Science Foundation of China had no role in the design, analysis or writing of this article.

\section{Availability of data and materials}

All data generated or analysed during this study are included in this published article and its Additional file 1.

\section{Authors' contributions}

$J Y$ and $L J$ conceived of the study, and participated in its design and coordination. LW, WL collected clinical data. LJ performed the CNP measurement. LW, WL and $Y Y$ interpreted the data. $L W$ and $W L$ contributed to the writing of the manuscript. All authors read and approved the final manuscript for submission.

\section{Ethics approval and consent to participate}

All subjects provided written informed consents. The study protocol was approved by the Institutional Ethical Committee of the Second Affiliated Hospital of Nanjing Medical University.
Consent for publication

Not applicable.

\section{Competing interests}

The authors declare that they have no competing interests.

\section{Publisher's Note}

Springer Nature remains neutral with regard to jurisdictional claims in published maps and institutional affiliations.

\section{Author details}

${ }^{1}$ Center for Kidney Disease, Second Affiliated Hospital of Nanjing Medical University, 262\# North Zhongshan Road, Nanjing 210003, China.

${ }^{2}$ Departments of nephrology, BenQ Medical Center, The Affiliated BenQ Hospital of Nanjing Medical University, Nanjing, China.

Received: 28 September 2017 Accepted: 19 February 2018

Published online: 05 March 2018

References

1. Sarnak MJ, Levey AS, Schoolwerth AC, Coresh J, Culleton B, Hamm LL, McCullough PA, Kasiske BL, Kelepouris E, Klag MJ, et al. Kidney disease as a risk factor for development of cardiovascular disease: a statement from the American Heart Association councils on kidney in cardiovascular disease, high blood pressure research, clinical cardiology, and epidemiology and prevention. Circulation. 2003;108(17):2154-69.

2. Weiner DE, Tighiouart H, Amin MG, Stark PC, MacLeod B, Griffith JL, Salem DN, Levey AS, Sarnak MJ. Chronic kidney disease as a risk factor for cardiovascular disease and all-cause mortality: a pooled analysis of community-based studies. J Am Soc Nephrol. 2004;15(5):1307-15.

3. Foley RN, Parfrey PS, Sarnak MJ. Clinical epidemiology of cardiovascular disease in chronic renal disease. Am J Kidney Dis. 1998;32(5 Suppl 3):S112-9.

4. Stenvinkel P, Carrero JJ, Axelsson J, Lindholm B, Heimburger O, Massy Z Emerging biomarkers for evaluating cardiovascular risk in the chronic kidney disease patient: how do new pieces fit into the uremic puzzle? Clin J Am Soc Nephrol. 2008;3(2):505-21.

5. Scotland RS, Ahluwalia A, Hobbs AJ. C-type natriuretic peptide in vascular physiology and disease. Pharmacol Ther. 2005;105(2):85-93.

6. Lumsden NG, Khambata RS, Hobbs AJ. C-type natriuretic peptide (CNP): cardiovascular roles and potential as a therapeutic target. Curr Pharm Des. 2010;16(37):4080-8.

7. Moyes AJ, Khambata RS, Villar I, Bubb KJ, Baliga RS, Lumsden NG, Xiao F, Gane PJ, Rebstock AS, Worthington RJ, et al. Endothelial C-type natriuretic peptide maintains vascular homeostasis. J Clin Invest. 2014;124(9):4039-51.

8. Nakao K, Kuwahara K, Nishikimi T, Nakagawa Y, Kinoshita H, Minami T, Kuwabara Y, Yamada C, Yamada Y, Tokudome T, et al. Endothelium-derived C-type natriuretic peptide contributes to blood pressure regulation by maintaining endothelial integrity. Hypertension. 2017;69(2):286-96.

9. Pierkes M, Gambaryan S, Boknik P, Lohmann SM, Schmitz W, Potthast R, Holtwick R, Kuhn M. Increased effects of C-type natriuretic peptide on cardiac ventricular contractility and relaxation in guanylyl cyclase A-deficient mice. Cardiovasc Res. 2002;53(4):852-61.

10. Beaulieu P, Cardinal R, Page P, Francoeur F, Tremblay J, Lambert C. Positive chronotropic and inotropic effects of C-type natriuretic peptide in dogs. Am J Phys. 1997;273(4 Pt 2):H1933-40.

11. Wright SP, Prickett TC, Doughty RN, Frampton C, Gamble GD, Yandle TG, Sharpe N, Richards M. Amino-terminal pro-C-type natriuretic peptide in heart failure. Hypertension. 2004;43(1):94-100.

12. Del Ry S, Maltinti M, Cabiati M, Emdin M, Giannessi D, Morales MA. C-type natriuretic peptide and its relation to non-invasive indices of left ventricular function in patients with chronic heart failure. Peptides. 2008;29(1):79-82.

13. Sangaralingham SJ, McKie PM, Ichiki T, Scott CG, Heublein DM, Chen HH, Bailey KR, Redfield MM, Rodeheffer RJ, Burnett JC Jr. Circulating C-type natriuretic peptide and its relationship to cardiovascular disease in the general population. Hypertension. 2015;65(6):1187-94.

14. Reference Values for Arterial Stiffness C. Determinants of pulse wave velocity in healthy people and in the presence of cardiovascular risk factors: 'establishing normal and reference values'. Eur Heart J. 2010;31(19):2338-50.

15. Azuma M, Chihara Y, Yoshimura C, Murase K, Hamada S, Tachikawa R, Matsumoto T, Inouchi M, Tanizawa K, Handa T, et al. Association between endothelial function (assessed on reactive hyperemia peripheral arterial 
tonometry) and obstructive sleep apnea, visceral fat accumulation, and serum adiponectin. Circ J. 2015;79(6):1381-9.

16. National Kidney F. K/DOQI clinical practice guidelines for chronic kidney disease: evaluation, classification, and stratification. Am J Kidney D. 2002; 39(2 Suppl 1):S1-266.

17. Rajendra Acharya U, Paul Joseph K, Kannathal N, Lim CM, Suri JS. Heart rate variability: a review. Med Biol Eng Comput. 2006;44(12):1031-51.

18. Cheung BM, Brown MJ. Plasma brain natriuretic peptide and C-type natriuretic peptide in essential hypertension. J Hypertens. 1994;12(4):449-54.

19. Igaki T, Itoh H, Suga S, Hama N, Ogawa Y, Komatsu Y, Mukoyama M, Sugawara A, Yoshimasa T, Tanaka I, et al. C-type natriuretic peptide in chronic renal failure and its action in humans. Kidney Int Suppl. 1996;55:S144-7.

20. Tsuji H, Larson MG, Venditti FJ Jr, Manders ES, Evans JC, Feldman CL, Levy D. Impact of reduced heart rate variability on risk for cardiac events. The Framingham Heart Study. Circulation. 1996;94(11):2850-5.

21. Buttgereit J, Shanks J, Li D, Hao G, Athwal A, Langenickel TH, Wright H, da Costa Goncalves AC, Monti J, Plehm R, et al. C-type natriuretic peptide and natriuretic peptide receptor B signalling inhibits cardiac sympathetic neurotransmission and autonomic function. Cardiovasc Res. 2016;112(3):637-44.

22. Buckley MG, Sethi D, Markandu ND, Sagnella GA, Singer DR, MacGregor GA. Plasma concentrations and comparisons of brain natriuretic peptide and atrial natriuretic peptide in normal subjects, cardiac transplant recipients and patients with dialysis-independent or dialysis-dependent chronic renal failure. Clin Sci. 1992;83(4):437-44

23. Joffy S, Rosner MH. Natriuretic peptides in ESRD. Am J Kidney Dis. 2005; 46(1):1-10.

24. Freda BJ, Francis GS. Natriuretic peptides and renal insufficiency: clinical significance and role of renal clearance. Heart Fail Clin. 2006;2(3):277-90.

25. Chun TH, Itoh H, Ogawa Y, Tamura N, Takaya K, Igaki T, Yamashita J, Doi K, Inoue M, Masatsugu K, et al. Shear stress augments expression of C-type natriuretic peptide and adrenomedullin. Hypertension. 1997;29(6):1296-302.

26. Suga S, Itoh H, Komatsu Y, Ogawa Y, Hama N, Yoshimasa T, Nakao K. Cytokine-induced C-type natriuretic peptide (CNP) secretion from vascular endothelial cells-evidence for CNP as a novel autocrine/paracrine regulator from endothelial cells. Endocrinology. 1993;133(6):3038-41.

27. Palmer SC, Prickett TC, Espiner EA, Yandle TG, Richards AM. Regional release and clearance of $\mathrm{C}$-type natriuretic peptides in the human circulation and relation to cardiac function. Hypertension. 2009;54(3):612-8.

28. Obineche EN, Pathan JY, Fisher S, Prickett TC, Yandle TG, Frampton CM, Cameron VA, Nicholls MG. Natriuretic peptide and adrenomedullin levels in chronic renal failure and effects of peritoneal dialysis. Kidney Int. 2006;69(1):152-6.

29. Prickett TC, Doughty RN, Troughton RW, Frampton CM, Whalley GA, Ellis CJ, Espiner EA, Richards AM. C-type natriuretic peptides in coronary disease. Clin Chem. 2017;63(1):316-24

30. Kenny AJ, Bourne A, Ingram J. Hydrolysis of human and pig brain natriuretic peptides, urodilatin, C-type natriuretic peptide and some C-receptor ligands by endopeptidase-24.11. Biochem J. 1993;291(Pt 1):83-8.

31. Matsukawa N, Grzesik WJ, Takahashi N, Pandey KN, Pang S, Yamauchi M, Smithies $\mathrm{O}$. The natriuretic peptide clearance receptor locally modulates the physiological effects of the natriuretic peptide system. Proc Natl Acad Sci U S A. 1999:96(13):7403-8.

32. Hunt PJ, Richards AM, Espiner EA, Nicholls MG, Yandle TG. Bioactivity and metabolism of C-type natriuretic peptide in normal man. J Clin Endocrinol Metab. 1994;78(6):1428-35.

33. Suga S, Nakao K, Itoh H, Komatsu Y, Ogawa Y, Hama N, Imura H. Endothelia production of $\mathrm{C}$-type natriuretic peptide and its marked augmentation by transforming growth factor-beta. Possible existence of "vascular natriuretic peptide system". J Clin Invest. 1992;90(3):1145-9.

34. Barletta G, Lazzeri C, Vecchiarino S, Del Bene R, Messeri G, Dello Sbarba A, Mannelli M, La Villa G. Low-dose C-type natriuretic peptide does not affect cardiac and renal function in humans. Hypertension. 1998;31(3):802-8.

35. Ono K, Mannami T, Baba S, Tomoike H, Suga S, Iwai N. A single-nucleotide polymorphism in C-type natriuretic peptide gene may be associated with hypertension. Hypertens Res. 2002;25(5):727-30.

\section{Submit your next manuscript to BioMed Central and we will help you at every step:}

- We accept pre-submission inquiries

- Our selector tool helps you to find the most relevant journal

- We provide round the clock customer support

- Convenient online submission

- Thorough peer review

- Inclusion in PubMed and all major indexing services

- Maximum visibility for your research

Submit your manuscript at www.biomedcentral.com/submit

C) Biomed Central 